\title{
SOBRE LA LOCALIZACIÓN DEL TOPÓNIMO ALMODÓVAR EN LA DESEMBOCADURA DEL SEGURA
}

\author{
Por \\ ANTONIO GARCIA MENARGUEZ
}

\section{Introducción}

Es una tendencia cada vez más generalizada en la investigación medieval la utilización del registro arqueológico para sustentar y/o completar la ausencia de fuentes documentales. En este sentido cabe interpretar los últimos trabajos realizados en yacimiento medievales del Bajo Segura; las excavaciones realizadas en el hinterland de la desembocadura del Segura; el Ribat de las Dunas (Azuar, 1986); el Baluarte de la Pólvora del Castillo de Guardamar (García-Menárguez y M. de Gea, 1986); el Cabezo de la Cueva de la Tía Maravillas en Rojales (Diz, García-Menárguez y M. de Gea, 1986) así como los yacimientos que ha excavado Emilio Diz en Orihuela (E. Diz, 1986), ya inciden en la problemática que, sobre historiografía medieval, ha suscitado la Vega Baja del Segura.

Con las consecuencias, todavía bastante complejas de estos trabajos, la lectura e interpretación de algunas fuentes documentales medievales y modernas que hemos podido manejar, algunos aspectos de toponimia $y$, fundamentalmente, los resultados de las últimas prospecciones arqueológicas de campo, hemos elaborado el presente trabajo, a modo de ensayo, para localizar el topónimo "Almodóvar» en un contexto arqueológico-espacial concreto: en el paraje denominado. "La Inquisición", a unos 3 kilómetros equidistante entre Rojales y Guardamar por el campo, justo allí donde ambos municipios dividen sus términos.

Esta hipótesis es diferente y contrasta, por tanto, con la admitida por la 
mayoría de investigadores, que lo situan e identifican con el actual Guardamar, en la desembocadura del río Segura (1).

\section{Yacimientos}

Saliendo de Rojales en dirección a Guardamar siguiendo la margen derecha del río Segura, hay una alineación de pequeñas elevaciones montañosas limitadas al este por la cañada de la Bernada y al oeste por la denominada cañada del Pino, ya en término de Guardamar. Se trata de un conjunto de cabezos y lomas redondeadas con altitudes que no sobrepasan los 100 metros, de formación caliza y escasa cobertura vegetal, a cuyos pies discurre serpenteando el río Segura. A espaldas de este conjunto, en actitud dominante, el Cabecico Soler.

En este marco geográfico, cercano a la desembocadura, con el curso del río Segura como vía natural de comunicación y control, potencial positivo de recursos, ha tenido lugar un prolongado asentamiento humano desde el Neolítico hasta nuestros días, alcanzando la máxima poblacional en época islámica (Fig. 1).

Hoy podemos afirmar, según las últimas prospecciones de campo, que el acceso de los árabes a la zona original un aumento sustancial de asentamientos en los cabezos de escasa altitud cercanos al curso del río, configurando una distribución espacial de habitad semi-disperso con funcionalidad diversa, sin precedentes históricos en las bocas del Segura.

El corpus de yacimientos que presentamos, pretende solamente dar una visión a grandes rasgos del poblamiento medieval en el área estudiada. En la mayoría de ellos no se han realizado excavaciones; en consecuencia, al carecer de estatigrafías, los datos cronológicos tienen carácter provisional.

\subsection{CABEZO DE LA CUEVA DE LA TÍA MARAVILLAS (Rojales)}

El yacimiento está situado a 1 kilómetro al este de Rojales sobre un cabezo en espolón de cima mesetada, de escasa altitud, a unos 300 metros del río Segura.

En 1986 se realizó una excavación de urgencia financiada por el propie-

(1) Hasta la fecha, de los autores que mantienen la asociación Almodovar-Guardamar, (Azuar, 1986, 571), (Barceló 1986, 68) y (Epalza 1980, 207), ha sido Mikel de Epalza quien ha concretado recientemente su hipótesis (en prensa) matizando opiniones anteriores (Epalza 1980). Para este autor: "Almodovar, por su significado, podría estar relacionado con la partida actualmente llamada La Redonda, en el meandro entre el río y el cerro del Castillo de Guardamar. El adjetivo Redonda es muy estraño en toponimia, pero se explicaria como traducción en romance del árabe mudawwar, urodeadon, o mudawwir, "rodeante", que corresponde a esa ubicación geográfica y estaría relacionado con el habitat del Castillo, pero a su pie y cerca del agua, como lo exige el urbanismo musulmán; las otras ubicaciones en alto corresponden a poblaciones cristianas". Agradecemos a Mikel de Epalza la amabilidad que ha tenido al proporcionarnos su trabajo en vias de publicación. Asimismo, todas aquellas sugerencias que han mejorado y han hecho posible la publicación del presente trabajo. 
tario de los terrenos, para poder edificar en la zona una caseta o almacén de aperos y otros usos (2).

Cronología: Por los materiales recogidos en excavación y prospección existen en el yacimiento dos culturales bien diferenciadas:

* Cultura islámica con materiales de una cronología aproximada desde finales del S.X hasta mediados del S. XII.

* Cultura bajomedieval con materiales de principios del S. XIV al S. XVI.

El área excavada en esta campaña sólo proporcionó materiales bajomedievales.

\subsection{CABEZO DE LAS TINAJAS (Rojales)}

A unos 500 metros del anterior yacimiento en dirección a Guardamar, entre el meandro del río y el camino que comunica Rojales y Guardamar por el campo, hay una pequeña loma de unos 18 metros de altura sobre el nivel del mar, en cuya superficie se encuentran varias sepulturas individuales de inhumación excavadas en la roca (3); restos de estructuras de muros de mampostería y al menos dos silos excavados en la misma roca.

Cronología: En superficie se ha recogido abundante material arqueológico: cerámica común, molinos giratorios de tracción humana y algunos fragmentos cerámicos con decoración verde y manganeso, cuerda seca parcial etc. Siglos X al XII aproximadamente.

\subsection{CABEZO DEL CANALES (Rojales)}

Sobre un pequeño cabezo de unos 22 metros de altitud, a unos 200 metros del río. Al terraplenar una pequeña loma anexa, aparecieron algunas bolsadas de ceniza con materiales arqueológicos: cerámica común; sobre todo marmitas decoradas con impresiones de peine con paralelos en el Ribat de las Dunas (4).

Cronología: Período Califal, siglos $X$ y XI.

\subsection{CEMENTERIO DEL CAMINO (Rojales)}

Al construirse el acceso que, desde el cabezo del Canales conduce al Ca-

(2) E. Diz, García-Menárguez y M. de Gea: «El Cabezo de las cuevas de la Tía Maravillas» Arqueología en Alicante 1.976-1986, Addenda I, Vega Baja del Segura. Pág. 29-31.

(3) Las tumbas de inhumación del Cabezo de las Tinajas ya fueron reseñados por Figueras Pacheco: "Geografía General del Reino de Valencia», Barcelona, tomo IV, pág. 134; y por Fernando Avilés: "Los toros hispánicos del Cabezo Lucero». Rojales (Alicante), 1.941, pág. 514.

(4) Gutiérrez Lloret, S.: "Avance para una tipología de las formas modeladas a mano del Ribat Califal de Guardamar del Segura (Alicante) n. 11. ${ }^{\circ}$ Congreso de Arqueología Medieval Española, Madrid, 1987. 
becico Soler, marcando el linde entre las fincas «Inquisición Pequeña y Grande», fueron exhumadas algunas tumbas de inhumación individual, a modo de fosa alargada, excavadas en la roca, con el esqueleto de costado, muy deteriorado, orientado al sudeste.

Cronología: Necropolis de época islámica. Siglos XI y XII.

\subsection{INQUISICIÓN GRANDE (Rojales)}

En una loma junto al camino de Guardamar, donde se asienta la casa, hoy en ruinas, de la Inquisición Grande, afloran en superficie restos de estructuras de muros de mamposteria y tapial.

Cronología: Por el material cerámico se puede deducir una datación de época islámica, con perduraciones en época moderna. Siglos XI y XIl.

\subsection{CABEZO DEL MORA (Guardamar)}

En una pequeña loma a unos 200 metros al este de la «Inquisición Grande», junto al tulud meridional, mucho más pronunciado que el resto de las vertientes, en término municipal de Guardamar, se conservan los restos de una estructura de forma cuadrangular; de 9 metros de lado, con factura de mortero de cal, sólo con recobo en su cara interna. Podría tratarse de un aljibe o cisterna para almacenar agua.

Cronología: Por los materiales cerámicos recogidos en superficie se podría fechar en época islámica, siglos XI y XII.

\subsection{CABEZO O CABECICO SOLER (Rojales)}

Cabezo aislado, de dificil acceso por todas sus laderas, máxima altitud de la zona, unos 87 metros sobre el nivel del mar. Desde la cima se domina la Bahía de Santa Pola, el Bajo Vinalopó y el Bajo Segura hasta la sierras de Hurchillo y Orihuela.

Etnológicamente el Cabezo soler está relacionado con la leyenda de «La Encantá" (5).

En superficie aparecen materiales arqueológicos que comprenden desde la Edad del Bronce hasta la Edad Media. De esta última etapa cultural se conservan algunos restos derruidos de un recinto amurallado de tapial.

Cronología: Yacimiento con amplia cronología: desde la Edad del Bronce 1.000 a. C., hasta el siglo XII, aproximadamente.

(5) Serra, Maria del Carmen; Román del Cerro, Juan Luis: Leyendas de la Vega Baja. Universidad de Alicante, 1986. 


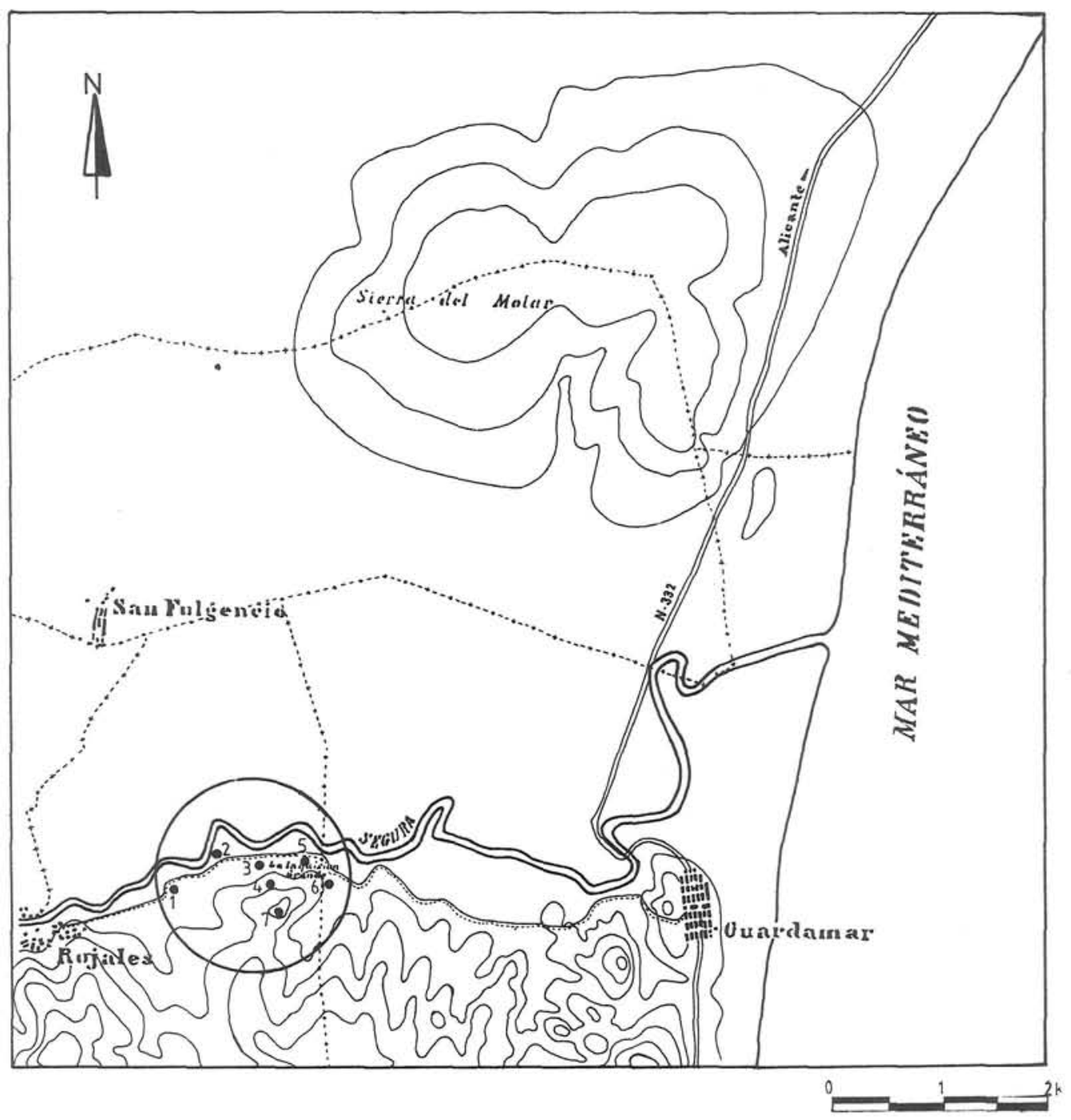

Fig. 1.- Distribución de yacimientos: 1. Cabezo de la Cueva de la Tía Maravillas (Rojales); 2. El Cabezo de las Tinajas (Rojales); 3. Cabezo del Canales (Rojales); 4. Cementerio del Camino (Rojales); 5. La Inquisición Grande (Rojales); 6. Cabezo del Mora (Guardamar); 7. Cabecico Soler (Rojales). 


\section{Fuentes documentales}

Las primeras referencias sobre el topónimo "Almodovar» proceden de las fuentes geográfico-descriptivas árabes. Al-'Udri, geógrafo almeriense del siglo XI, al describir el territorio de Tudmir y el río del mismo nombre -el Segura - dice: "Su cauce concluye al sur de este paraje, en la "náhiya" llamada de "Al-Muwallidin»; en dirección a la alqueria conocida por "Al-Juzayra". De allí el río se dirige hacia el mar, siendo conocido aquel lugar con el nombre de "Al-Mudawwi" (6).

Un siglo posterior, Al-Idrisi nombra de nuevo el mismo topónimo: "... después se dirige directamente al mediodía, - se refiere al río Segura-, pasando cerca del Fuerte del Ferez, de Mula, de Murcia, de Orihuela, de Almodovar y desagua en el mar...» (7).

Con posterioridad a estas citas árabes, las fuentes históricas que documentan el topónimo pertenecen a un período inmediatamente posterior a la reconquista castellana por Alfonso $X$ del reino de Murcia. Así, el 15 de julio de 1.266, el rey sabio confirma, desde Sevilla, el primer reparto hecho a la ciudad de Orihuela. la Villa recibió: Abanilla, Albatera, Almodovar, Arrabal, Cox y Crevillente (8). Por estas mismas fechas se hace referencia a Almodovar en el Repartimiento de Orihuela (9). A partir de este momento, Almodovar no aparece en las fuentes bajo-medievales cristianas, en su lugar se cita Guardamar en la costa (10) y Rojales al interior (11). No obstante, se mantienen las alusiones al topónimo Almodovar, hasta el siglo XIV, en los textos árabes granadinos dirigidos a la corona de Aragón (12).

En el siglo XVII, en época cristiana tardía, aparece de nuevo el topónimo Almodovar en la obra del Teólogo Francisco Martínez Paterna (13). El autor, al describir los pueblos de Orihuela, dice:... "Roxales parte término con la heredad llamada La Marquesa... y de todo el campo hasta las salinas por el que llaman de La Mata, y de huerta partía mojones con Elche y Guardamar y Almodovar por la parte del campo. Era (Almodovar) muy vecina población de tiempos de moros la cual asolaron los cristianos con su castillo cuando recu-

(6) Molina López: «La Cora de Tudmir, según Al’Udri, S. Xl, aportaciones al estudio geográfico-descriptivo del S.E. penínsularn. Cuadernos de Historia del Islam, número 3, Granada, 1953.

(7) Idrisi, Al: Desciption de l'Afrique et de l'Espagne, Ed. R. Dozy et M.J. de Goeje (reimprèssion). Leiden 1968.

(8) Martínez Morella, V: “Carta de los Reyes de Castilla a Orihuela" 1265-1295. Alicante, 1954 pags. 26-33.

(9) Vease J. Torres Fontes: El Repartimiento de Orihuela, Murcia 1988, pags. 3 y ss.

(10) A finales del S. XIII Guardamar se incorpora por Jaime II a la corona de Aragón; vease Del Estal, $M$.: EI Reino de Murcia bajo Aragón (1236-1305) Alicante, pag. 26. Consultese también Llobregat Conesa, E.: "La toponimia litorial valenciana en el "Atlas Catalán» de Gresques Abraham (A.D. 1375)", Revista Instituto de Estudios Alicantinos, 24 (1978), pag. 66.

(11) Vilar, J. Bautista: Los siglos XIV-XV en Orihuela, Murcia, 1977, pag. 28.

(12) Alarcón y Santón et Alii: Los documentos árabes diplomáticos del Archivo de la Corona de Aragón, Madrid, 1940.

(13) Martínez Paterna, F.: Historia de la Ciudad de Orihuela Orihuela, 1632, 39 fols. 
peraron a España. Estaba fundada Almodovar a la falda de un cerro, y tenía por término lo mejor de este paraje con una laguna de agua de cielo donde se crian muchos anades (era de los gallegos y la vendieron) y se coge en su término mucho trigo, cebada y arroz y caza. Fue Almodovar fortaleza grande donde se defendieron los habitantes en ella de sus enemigos y a la otra parte del río hay grandes saladares, hoy se crian muchos oruscus que decimos los valencianos regalicia. Hoy es la casa de don Mariano Rocan.

A principios de este siglo, Gisbert y Ballesteros vuelve a incidir sobre el topónimo: "Modovar o Al'Modovar fue una población con fortaleza ... El nombre de Almoradí parece aludir a Al'Modovar...; no obstante junto al Segura y cerca de Rojales existe una finca denominada "Casa Grande de Almodovar», de donde proviene el título condado de Almodovar» (14).

\section{Consideraciones finales}

Si analizamos e interpretamos el conjunto de las fuentes documentales cronologicamente, podemos comprobar que existen bastantes elementos de juicio que sustentan nuestra hipótesis. Así, por ejemplo, en el texto de Al'Udri para Molina López (15), el topónimo significa "dar vueltas» o "meandrizar» (16), y hace referencia, en sentido geográfico a un nombre de tema fluvial donde termina asentándose la población (17) lo que parece desprenderse un siglo posterior si en el texto de Al'Idrisi el topónimo hiciera referencia a una alquería o núcleo poblacional, como sugiere Rafael Azuar (18). Así se deduce también por la prospección arqueológica.

A raiz de la Conquista Cristiana, en la segunda mitad del siglo XIII, existen en las fuentes documentales cierta confusión y complejidad. Así sucede en el Repartimiento de Orihuela cuando se produce el cambio de la población con un nuevo asentamiento en Guardamar (19). A partir de estas fechas ya no consta Almodovar en la documentación medieval; quizás porque dejó de existir a raíz de la revuelta mudéjar. Esta premisa y el cambio de asentamiento (20) pueden explicar, a nuestro juicio, la aparición del topónimo Guardamar, población de nueva planta que, por su importante situación estratégica

(14) Gisbert y Ballesteros, E.: Historia de Orihuela, Orihuela 1901, tomo I, pag. 41.

(15) Molina López, op. cit. pag. 46.

(16) Es elocuente, en este sentido, comprobar que el lugar donde más proliferan los meandros, corresponde a la zona intermedia entre Rojales y Guardamar.

(17) Cfr. Mikel de Epalza: "Al toponimo de Guardamar", Revista del/nstituto de Estudios Alicantinos, número 29, Alicante $1980 \mathrm{pag} .206$.

(18) Azuar, R.: Castellologia Medieval Alicantina Instituto de Estudios Alicantinos, Alicante 1981, pags. 206 y ss.

(19) En la cuarta partición del Repartimiento de Orihuela, después de citar alternativamente a Guardamar y Almodovar, dice: «E fallamos que en los que avemos heredados en Guardamar, que avie XVII personas que non moravan y ni façiem casas en el castello como el rey mandaran Torres Fontes, Op. cit. pag. 60.

(20) Torres Fontes (1988) admite que el cambio de población a Guardamar se produce desde la llegada de Jaime I y la confirmación del privilegio del 15 de julio de 1266 , por Alfonso $X$ el Sabio. 
junto al mar, se mantendrá en ambigua independencia de la gobernación de Orihuela, hasta que Pedro IV, el 24 de noviembre de 1364, amparándose en el privilegio de Alfonso $X$ de 1.266: "otorga que lloch de Almodovar lo cual es ara appellat Guardamar, fos de la villa de Oriola ab fots sos termens, fous e postures, lo qual donat sub era Millessima ccc. III» (21).

Esta sentencia reguladora de la situación jurisdiccional de Guardamar con Orihuela, supone que Guardamar y Almodovar se suceden en el tiempo, pero no en el espacio, como prodremos ver.

La identificación de Almodovar con Guardamar que sugiere la sentencia de Pedro IV, aunque extraña que no conste en los Anales de Mosen Bellot (22) ha sido propuesta recientemente por Carmen Barcelo (23) y Rafael Azuar (24), a raiz del descubrimiento de una Rábita islámica en las dunas de Guardamar. Este yacimiento fechado en el siglo $X$, se abandona, según Azuar, su excavador, a causa de los terremotos, trasladándose la población al Castillo de Guardamar, ya que si... "el texto de Al’Udri no menciona la Rábita, a pesar de su importancia, el Almodovar de los textos de los siglos XI-XII hace referencia al actual Guardamar" (25). Sin embargo, en el estado actual de la investigación, esta hipótesis no se puede mantener. Las excavaciones en curso en el Baluarte de la Pólvora del Castillo de Guardamar demuestran que el registro arqueológico de los niveles más antiguos de habitat medieval, intramuros y extramuros de las murallas de levante, corresponden a época cristiana (26); los escasos elementos arqueológicos de época islámica: cerámicas estampilladas y esgrafiadas son bastante tardias, de mitad del siglo XIII, perdurando incluso en época bajomedieval (27). Luego, si la Rábita se abandona a mitad del siglo XI y el Castillo de Guardamar tiene un origen bajomedieval de mediados o finales del siglo XIII ¿Dónde se localiza el poblamiento islámico desde mediados del siglo XI a mediados del siglo XIII?

Entendemos, pues, que mientras futuras investigaciones arqueológicas o documentales, no demuestren lo contrario, el Almodovar de los textos árabes se encuentra en algún paraje sin localizar, no lejos de la desembocadura, o bien se localiza, como hemos propuesto, más al interior, entre Rojales y Guardamar, lugar mucho más seguro del terremoto y del avance de la duna litoral,

(21) Blasco, Rosa: "Sobre la anexión de Guardamar a Orihuela» Anales de la Universidad de Alicante, pag. $79 / 86$.

(22) Franco Sánchez, F.: Estudio de los Espacios Urbanos de la ciudad de Orihuela en el Período Islámico. Tesina inédita de Licenciatura de la Universidad de Alicante. Alicante, 1986, pag. 337.

(23) Barcelo Torres, C.: «Almodovar, una población de la Cora de Tudmir sepultada en las Dunas de Guardamar del Segura», Saitabi, Valencia XXXV, 1985, pag. 68.

(24) Azuar Ruiz, R.: "Una Rabita Califal en las dunas de Guardamar" Actas del I Congreso de Arqueologra Medieval Española. Zaragoza, 1986, pag. 511.

(25) Azuar, op. cit. pag. 512.

(26) Un avance preliminar donde se incide en la problemática cronológica del Castillo de Guardamar, se puede ver en García-Menarguez y M. de Gea: "Baluarte de la Pólvora del Castillo de Guardamar», Arqueología en Alicante 1976-1986. Addenda I, Vega Baja del Segura. Alicante 1986. Pags. 32-33.

(27) Navarro Palazón, J.: «La Cerámica Esgrafiada Andalucsí en Murcia. Publicaciones de la Casa de Velazquez, Madrid 1986. 
donde ya existía, a la sazón, un asentamiento anterior con fuerte sustrato desde época precalifal (28).

Un intento similar, aunque por diferente motivos, será una constante durante la Baja Edad Media (29). Queda implícito, asimismo, que un asentamiento más al interior, no significa dejar sin vigilancia la línea de costa (30).

Como conclusión final, traemos a colación el texto de Martínez Paterna; la localización y descripción del contexto geográfico, así como la propiedad mobiliar (31) del lugar donde hemos situado el topónimo, coinciden, en síntesis, con el corpus de fuentes documentales manejadas, $y$, sobre todo, con el registro arqueológico.

(28) Se va confirmando, cada vez más de acorde con las fuentes históricas de la alta Edad Media, la existencia de un poblamiento generalizado en época tardorromana o precalifal en el Bajo Segura. Para el área que nos ocupa. Cfs, Gutiérrez Lloret, S: "Boletín de Arqueología Medieval, número 1, Madrid, 1987, pags. 7-23.

(29) Vilar, J. Bautista: op. cit. pags. 28-29.

(30) Durante la alta Edad Media, además del Ribat de las Dunas, la vigilancia y control de la línea de costa debío realizarse, como ha sido costumbre hasta el siglo XVIII, mediante torres almenaras. Los restos de una de ellas, de planta rectangular, realizada con factura de tapial, ha sido descubierta recientemente a escasos metros de la planta de Guardamar, en la Partida del Moncayo.

(31) Don Mariano Roca de Togores era señor de la Daya Vieja; del Barranco de Benejuzar y Conde de Pinohermoso, según el Barón de Finestrat: "Nobiliario alicantino", Instituto de Estudios Alicantinos, Alicante, 1983, pag. 245. El escudo de la fachada de la casa de la «nquisición grande" posee las armas de la familia Roca de Togores; con anterioridad al topónimo "Inquisición grande» bien se pudo llamar "Casa grande de Almodovar" como reza en el texto de Gisbert Ballesteros. 